\title{
Hubungan Antara Fleksibilitas Pergelangan Tangan dan Power Otot Lengan Dengan Ketepatan dan Kecepatan Smash Pada Cabang Olahraga Bulutangkis Teddy Gunawan, Agus Rusdiana
}

Program Studi Ilmu keolahragaan, Departemen Pendidikan Kesehatan dan Rekreasi, Fakultas Pendidikan Olahraga dan Kesehatan, Universitas Pendidikan Indonesia, Indonesia

\begin{tabular}{l}
\hline Info Artikel \\
\hline Sejarah Artikel: \\
Diterima: Oktober-2018 \\
Disetujui: Oktober-2018 \\
Dipublikasikan : Oktober-2018 \\
\hline Kata Kunci: \\
Bulutangkis, fleksibilitas \\
pergelangan tangan, power otot \\
lengan, ketepatan smash, \\
kecepatan smash \\
\hline
\end{tabular}

kecepatan smash

\begin{abstract}
Abstrak
Tujuan dari penelitian ini untuk mengetahui hubungan antara fleksibilitas pergelangan tangan dan power otot lengan dengan hasil ketepatan dan kecepatan smash pada cabang olahraga bulutangkis. Penelitian ini menggunakan metode kuantitatif dengan studi korelasional. Populasi yang digunakan pada penelitian ini adalah 30 orang anggota UKM Bulutangkis UPI Bandung dengan menggunakan teknik random sampling di dapat sampel sebanyak 20 orang. Instrumen yang digunakan dalam penelitian ini adalah alat ukur goniometer, tes soft ball throw, tes ketepatan dan tes kecepatan smash dengan aplikasi kinovea. Dengan hasil penelitian fleksibilitas pergelangan tangan dengan hasil ketepatan smash adalah $r=0.703$, nilai sig. $0.001<$ 0.05 , dengan kecepatan smash $r=0.592$, nilai sig. $0.006<0.05$, sedangkan hasil penelitian power otot lengan dengan hasil ketepatan smash adalah $r=0.481$, nilai sig. $0.032<0.05$, dengan hasil kecepatan smash $r=0.625$, nilai sig. $0.003<0.05$. Dan fleksibilitas pergelangan tangan dan power otot lengan secara bersama-sama hasil ketepatan smash adalah $\mathrm{r}=0.758$, nilai sig. $0.001<0.05$, dengan kecepatan smash $\mathrm{r}=$ 0.754 , nilai sig. $0.001<0.05$. Menunjukkan bahwa terdapat hubungan antara fleksibilitas pergelangan tangan dan power otot lengan dengan hasil ketepatan dan kecepatan smash.
\end{abstract}

\begin{abstract}
The purpose of this study was to determine the relationship between wrist flexibility and arm muscle power with the results of the accuracy and speed of smash in badminton. This study uses quantitative methods with correlational studies. The population used in this study were 30 members of the UPI Bandung Badminton UKM using random sampling techniques in which 20 people were sampled. The instruments used in this study were goniometer measuring devices, soft ball throw tests, accuracy tests and smash speed tests with kinovea applications. With the results of the study of wrist flexibility with the results of the accuracy of the smash is $r=0.703$, the sig value. $0.001<0.05$, with the speed of smash $r=0.592$, the value of sig. $0.006<0.05$, while the results of the study of arm muscle power with the results of the smash accuracy are $r=0.481$, the sig value. $0.032<0.05$, with the results of the smash speed $r=0.625$, the sig value. $0.003<0.05$. And the flexibility of the wrist and arm muscles together, the result of the accuracy of the smash is $r=0.758$, the sig value. $0.001<0.05$, with the smash speed $r=0.754$, the sig value. 0.001 $<0.05$. Indicates that there is a relationship between wrist flexibility and arm muscle power with the results of smash accuracy and speed.
\end{abstract}

(C) 2018 Universitas Pendidikan Indonesi

\footnotetext{
Alamat korespondensi:

Gedung FPOK Lantai 2 FPOK UPI

Universitas Pendidikan Indonesia, Jl. Dr. Setiabudhi No. 299 Bandung

E-mail: teddygunawan165@gmail.com
}

eISSN: 2549-6360 


\section{PENDAHULUAN}

Bulutangkis adalah cabang olahraga permainan yang sudah banyak dikenal oleh masyarakat Indonesia maupun Internasional. Permainan bulutangkis dilakukan dengan menggunakan raket, dan shuttlecocks sebagai alat bermain dengan saling berhadapan satu sama lain pada sebuah lapangan yang dibatasi oleh sebuah net, seperti yang telah di ungkapkan oleh Subarjah dan Hidayat (2007), mengemukakan bahwa Permainan bulutangkis adalah suatu permainan yang saling berhadapan satu orang lawan satu orang atau dua orang lawan dua orang dengan menggunakan raket dan saatelkok sebagai alat permainan, bersifat perseorangan yang dimainkan pada lapangan tertutup maupun terbuka dengan lapangan permainan beruba lapangan yang datar terbuat dari lantai beton, kayu atau karpet yang ditandai dengan garis sebagai batas lapangan dan dibatasi oleh net pada tengah lapangan permainan.

Pada permainan olahraga bulutangkis, keterampilan dalam memukul adalah dasar untuk dapat bermain bulutangkis dengan baik, hal ini seperti juga di ungkapkan oleh Tohar (1991) yang di tulis dalam Subardjah dan Hidayat (2007) mengatakan bahwa, Keterampilan dasar merupakan salah satu jenis keterampilan yang harus dipahami dan dikuasai oleh setiap pemain dalam melakukan kegiatan bermain bulutangkis karena merupakan salah satu pendukung pokok prestasi olahraga. Macam-macam teknik pukulan dalam bulutangkis sangat penting dalam mencari poinpoin untuk kemenangan. Namun, dari beberapa macam teknik pukulan tersebut hanya pukulan smash yang memiliki sifat menyerang artinya pukulan tersebut adalah pukulan yang paling banyak menghasilkan poin.

Pukulan smash merupakan salah satu pukulan yang mengakhiri terjadinya rally, biasanya seorang pemain melakukan smash untuk mematikan lawan dan mengakhiri terjadinya rally sehingga mendapatkan poin. Pukulan smash identik dengan pukulan offensive cepat dan menukik tajam dalam proses menyerang ke area lawan. Subarjah dan Hidayat
(2007) mengatakan "Pukulan smash merupakan pukulan yang keras dan tajam yang bertujuan untuk mematikan lawan secepat-cepatnya".

Pukulan smash membutuhkan komponen kondisi fisik seperti kekuatan dan kecepatan, untuk dapat menghasilkan pukulan yang keras dan tajam, Subarjah dan Hidayat (2007) mengemukakan bahwa Pada pukulan ini lebih mengandalkan kekuatan, kecepatan, lengan dan lecutan pergelangan tangan. Kuat dan cepat atau yang sering disebut sebagai power adalah komponen yang harus diperhatikan dengan baik agar dapat meningkatkan kualitas smash yang dilakukan. Lecutan pada pergelangan tangan membutuhkan ruang gerak sendi yang luas dan fleksibel yang artinya bahwa fleksibilitas pergelangan tangan juga merupakan komponen kondisi fisik yang penting diperhatikan agar dapat menunjang pada hasil smash yang dilakukan.

Fleksibilitas adalah salah satu komponen kondisi fisik yang penting untuk ditingkatkan sebagai penunjang dalam smash. Fleksibilitas identik dengan ruang gerak sendi. Menurut Harsono (2016), Fleksibilitas adalah kemampuan untuk melakukan gerakan dalam ruang gerak sendi. Orang yang memiliki fleksibilitas yang baik akan memiliki ruang gerak sendi yang luas, hal ini akan juga berdampak pada kualitas suatu keterampilan. Fleksibilitas pergelangan tangan yang baik akan memberikan kualitas keterampilan yang baik seperti pada pukulan smash.

Pukulan smash merupakan pukulan yang cepat dan kuat. Artinya bahwa komponen kondisi fisik yang identik sama dengan karakteristik dari pukulan tersebut adalah kekuatan dan kecepatan. Power adalah kekuatan yang dilakukan dengan cepat. Harsono (2016) mengatakan Power adalah kemampuan otot untuk mengerahkan kekuatan maksimal dalam waktu yang sangat cepat. Memiliki power pada otot lengan dengan baik akan memungkinkan hasil yang baik pada sebuah pukulan smash yang dilakukan.

Smash dalam cabang olahraga bulutangkis merupakan salah satu pukulan yang 
banyak menghasilkan poin. Smash merupakan pukulan cepat dan menukik tajam. Namun jika hasil pukulan tersebut tidak tepat sasaran akan sangat merugikan. Seperti yang sudah dijelaskan tadi bahwa ciri dari pukulan smash adalah menukik tajam dengan tujuan tepat sasaran. Untuk menghasilkan sebuah pukulan smash yang menukik tajam, maka dibutuhkan pergelangan tangan yang dapat menekuk raket lebih kedalam agar hasil didapat bisa lebih maksimal yang artinya butuh ruang gerak sendi yang luas pada pergelangan tangan atau disebut fleksibilitas pergelangan tangan. Seperti yang telah dijelaskan sebelumnya cepat adalah ciri dari pukulan smash, untuk dapat melakukan sebuah pukulan seperti itu maka power memerankan peran penting terhadap hasil pukulan smash yang cepat. Fleksibilitas pergelangan tangan dan power otot lengan adalah komponen kondisi fisik yang berperan penting pada hasil ketepatan dan kecepatan pukulan smash dalam olahraga bulutangkis.

Penelitian sebelumnya mengungkapkan bahwa fleksibilitas pergelangan tangan memiliki korelasi terhadap ketepatan spike pada permainan bola voli (Ruswandi, 2016). Selain itu juga penelitian sebelumnya mengungkapkan bahwa power otot lengan dan otot tungkai memiliki korelasi dengan hasil spike semi pada cabang olahraga bola voli (Heldayana, 2014). Dari kedua penelitian tersebut menjelaskan bahwa komponen kondisi fisik fleksibilitas pergelangan tangan dan power otot lengan menentukan pada hasil ketepatan pada permainan voli. Namun penelitian tentang fleksibilitas pergelangan tangan dan power otot lengan juga perlu diteliti pada cabang olahraga lain yang lebih spesifik pada ketepatan dan kecepatan, salah satunya seperti pada pukulan smash di cabang olahraga bulutangkis.

Berdasarkan pentingnya melihat komponen kondisi fisik yang dapat menunjang terhadap hasil ketepatan dan kecepatan smash pada cabang olahraga bulutangkis yang sudah dipaparkan di atas, maka penelitian ini ingin melihat hubungan antara fleksibilitas pergelangan tangan dan power otot lengan dengan hasil ketepatan dan kecepatan smash pada cabang olahraga bulutangkis. Berdasarkan latar belakang penelitian yang telah diuraikan di atas, maka permasalahan yang akan dikaji dalam penelitian ini adalah:

1. Adakah hubungan antara fleksibilitas pergelangan tangan dengan ketepatan pukulan smash pada cabang olahraga bulutangkis?

2. Adakah hubungan antara fleksibilitas pergelangan tangan dengan kecepatan pukulan smash pada cabang olahraga bulutangkis?

3. Adakah hubungan antara power otot lengan dengan ketepatan pukulan smash pada cabang olahraga bulutangkis ?

4. Adakah hubungan antara power otot lengan dengan kecepatan pukulan smash pada cabang olahraga bulutangkis ?

5. Adakah hubungan antara fleksibilitas pergelangan tangan dan power otot lengan secara bersama-sama dengan ketepatan pukulan smash pada cabang olahraga bulutangkis?

6. Adakah hubungan antara fleksibilitas pergelangan tangan dan power otot lengan secara bersama-sama dengan kecepatan pukulan smash pada cabang olahraga bulutangkis?

\section{METODE}

Sugiyono menjelaskan (2013) bahwa, Metode penelitian adalah sebagai cara ilmiah untuk mendapatkan data dengan tujuan dan kegunaan tertentu. Metode penelitian yang digunakan pada penelitian ini adalah korelasional. Arikunto (2010) menjelaskan bahwa, Penelitian korelasional adalah penelitian yang dilakukan oleh peneliti untuk mengetahui tingkat hubungan antara dua variabel atau lebih, tanpa melakukan perubahan, tambahan atau manipulasi terhadap data yang memang sudah ada. Populasi dalam penelitian ini adalah anggota UKM Bulutangkis Universitas Pendidikan Indonesia yang berjumlah 30 orang. Menggunakan purposive sampling maka sampel penelitian ditetapkan berjumlah 20 orang. 
Penggunaan teknik purposive sampling di dasarkan atas beberapa syarat. Syarat tersebut seperti yang di jelaskan Arikunto, S. (2010) sebagai berikut:

- Pengambilan sampel harus didasarkan atas ciri-ciri, sifat-sifat atau karakteristik tertentu, yang merupakan ciri-ciri pokok populasi.

- Subjek yang diambil sebagian sampel benar-benar merupakan subjek yang paling banyak mengandung ciri-ciri yang terdapat pada populasi (key subjectis).

- Penentuan karakteristik populasi dilakukan dengan cermat di dalam studi pendahuluan.

Instrumen yang digunakan adalah goniometer yang memiliki validitas 0,97 dan reliabilitas 0,51 (Supriatna dalam Ruswandi 2016), alat ini bertujuan untuk mengukur fleksibilitas pergelangan tangan, tes soft ball throw dengan validitas 0,85 dan reliabilitas 0,77 (Nurhasan dan Cholil, 2007) yang bertujuan untuk mengukur power otot lengan, tes ketepatan smash yang bertujuan untuk mengukur kemampuan dan skill memukul smash, dan tes kecepatan smash menggunakan video visual (kamera) untuk menangkap hasil gambar/video yang kemudian dianalisis dengan aplikasi software kinovea, tujuannya untuk mengukur kecepatan bola (shuttlecock). Pengolahan data pada penelitian ini dengan menggunakan statistik korelasi dan regresi.

\section{HASIL}

Berdasarkan hasil analisis data yang sudah dilakukan oleh peneliti yaitu menggunakan statsitika deskriptif, diperoleh bahwa peneliti memperoleh gambaran tingkat kecemasan wasit pada sebelum, selama dan sesudah memimpin pertandingan futsal. Hasil analisis angket yang terdiri dari sebelum, selama dan sesudah memimpin pertandingan futsal dari 15 sampel. Terhitung jumlah 1144 untuk skor angket sebelum,dan itu mengindikasikan bahwa tingkat kecemasan wasit pada kategori sedang, kemudian 1441 untuk skor angket selama yang mengindikasikan bahwa tingkat kecemasan wasit pada kategri tinggi dan 463 untuk skor angket sesudah, skor tersebut mengindikasikan bahwa kecemasan wasit pada kategori rendah. Mengacu terhadap tabel kriteria dapat disimpulkan bahwa tingkat kecemasan wasit sebelum termasuk kategori kecemasan sedang dengan rata-rata denyut nadi 99 BPM termasuk klasifikasi normal. Tingkat kecemasan wasit selama termasuk kategori kecemasan tinggi dengan rata-rata denyut nadi aktivitas fisik 141 BPM termasuk klasifikasi cepat/takikardi. Dan tingkat kecemasan wasit sesudah termasuk kategori kecemasan rendah dengan rata-rata denyut nadi 68 BPM termasuk klasifikasi normal.

Gambar 1. Hasil Gambaran Skor Angket

Tingkat Kecemasan Sebelum, Selama dan

Sesudah Memimpin Pertandingan Futsal

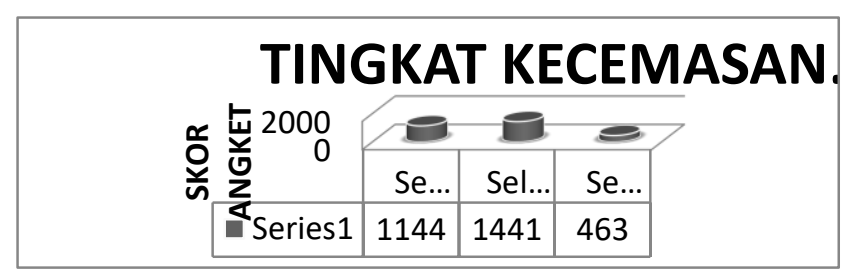

\begin{tabular}{|c|c|c|}
\hline \multicolumn{3}{|c|}{ Wasit } \\
\hline No & Denyut Nadi & BPM \\
\hline 1 & Sebelum Memimpin Pertandingan & 99 \\
\hline 2 & Selama Memimpin Pertandingan & 141 \\
\hline & (Aktivitas Fisik) & \\
\hline 3 & Sesudah Memimpin Pertandingan & 68 \\
\hline
\end{tabular}

\section{KESIMPULAN}

Berdasarkan hasil analisis data yang diperoleh dan uraian yang telah dikemukakan, maka kesimpulan yang peneliti ambil dari hasil penelitian ini adalah sebagai berikut:

1. Terdapat Hubungan Antara Fleksibilitas Pergelangan Tangan dengan Hasil Ketepatan Smash Pada Cabang Olahraga Bulutangkis.

2. Terdapat Hubungan Antara Fleksibilitas Pergelangan Tangan dengan Hasil 
Kecepatan Smash Pada Cabang Olahraga Bulutangkis.

3. Terdapat Hubungan Antara Power Otot Lengan dengan Ketepatan Smash Pada Cabang Olahraga Bulutangkis.

4. Terdapat Hubungan Antara Power Otot Lengan dengan Kecepatan Smash Pada Cabang Olahraga Bulutangkis.

5. Terdapat Hubungan Antara Fleksibilitas Pergelangan Tangan dan Power Otot Lengan dengan Ketepatan Smash Pada Cabang Olahraga Bulutangkis.

6. Terdapat Hubungan Antara Fleksibilitas Pergelangan Tangan dan Power Otot Lengan dengan Kecepatan Smash Pada Cabang Olahraga Bulutangkis.

Keterbatasan waktu, biaya, dan tenaga masih menjadi kekurangan dalam penelitian ini untuk itulah diharapkan pada penelitian lebih lanjut dapat dilakukan dengan jumlah sampel yang lebih luas dan kajian yang lebih mendalam. Selain itu untuk penelitian lebih lanjut disarankan untuk meneliti komponen kondisi fisik lainnya yang dapat menunjang terhadap pukulan smash seperti kekuatan pergelangan tangan, reaksi, stabilisasi. Selain itu juga disarankan untuk mencoba meneliti keterampilan-keterampilan dalam cabang olahraga bulutangkis lainnya seperti Dropshot, Netting, Lob..

\section{DAFTAR PUSTAKA}

Arikunto (2010). Prosedur penelitian (suatu pendekatan praktik). Jakarta: Rineka Cipta.

Harsono. (2016). Latihan kondisi fisik (untuk atlet dan kesehatan). Bandung: FPOK-UPI Bandung.

Heldayana (2014). Hubungan antara power otot lengan dan otot tungkai dengan hasil spike semi pada cabang olahraga bola voli. (Skripsi).

Pendidikan Kepelatihan Olahraga, Universitas Pendidikan Indonesia, Bandung.

Hermansyah (2017). Hubungan power otot lengan dan koordinasi dengan kecepatan dan ketepatan smash dalam cabang olahraga bulutangkis. (Skripsi). Pendidikan Kepelatihan Olahraga, Universitas Pendidikan Indonesia, Bandung.

Nurhasan dan Cholil (2007). Tes dan pengukuran keolahragaan. Bandung: Universitas Pendidikan Indonesia.

Ruswandi (2016). Hubungan power otot lengan dan fleksibilitas pergelangan tangan terhadap hasil ketepatan melakukan spike pada permainan bola voli. (Skripsi). Pendidikan Kepelatihan Olahraga, Universitas Pendidikan Indonesia, Bandung.

Sugiyono. (2013). Metode penelitian pendidikan. Bandung: Alfabeta.

(2013). Statistika untuk penelitian. Bandung: Alfabeta. Psychology. Champaign, IL: Human Kinetics. 